\title{
Flow Macrocyclization Using Copper Tubing
}

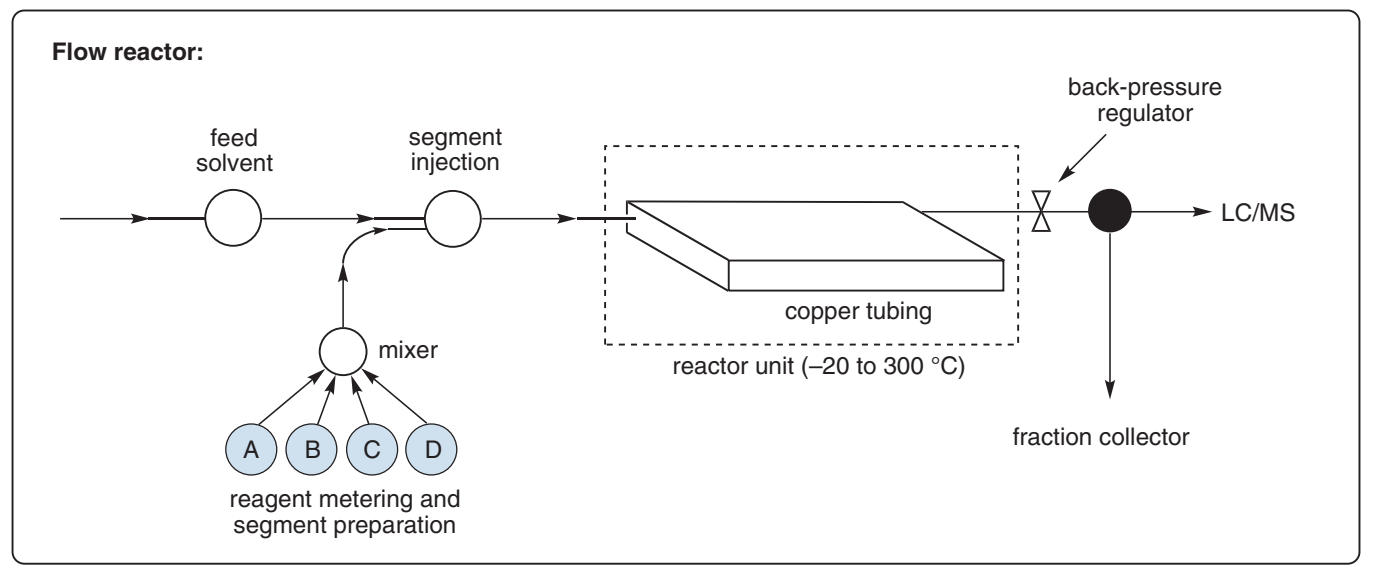

Flow macrocyclization reaction:<smiles>C#CCOC(C)C(C)N(C)C(=O)CCCN</smiles>

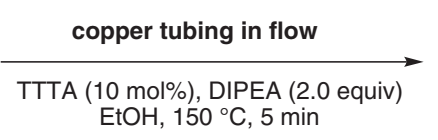

TTTA: tris[(1-tert-butyl-1H-1,2,3-triazolyl)methyl]amine<smiles>CCCOCc1cnn(CCCC(=O)N(C(=O)[N+](=O)[O-])C(C)C)c1</smiles>

2

$73 \%$ isolated yield

Significance: Flow macrocyclization with a copper surface catalyst via the azide-acetylene cycloaddition reaction was described. The flow macrocyclization of an azidealkyne $\mathbf{1}$ with TTTA and DIPEA was performed in copper tubing ( $3 \mathrm{~m}$ length, $0.75 \mathrm{~mm}$ inner diameter) to give the triazole-containing macrocycle $\mathbf{2}$ in 73\% isolated yield within five minutes of residence time without addition of extraneous copper(l) salt in the reaction mixture. The structure of the 12-memberd macrocycle $\mathbf{2}$ was confirmed by X-ray crystallography.
Comment: A series of 12- to 22-membered macrocycles was prepared under similar flow conditions (14 examples, 28-90\% yield). Elemental analysis in the ethanolic reaction mixture indicated less than 5 ppm of copper. In flask reactions, refluxing the reaction mixture of azidealkyne $\mathbf{1}$, TTTA, and DIPEA in ethanol with copper turnings gave no detectable product $\mathbf{2}$ after five minutes, and only a trace amount of $\mathbf{2}$ after 90 min. Under similar conditions, Cul (0.2 or 1.0 equiv) was also not effective. 